\title{
Sex differences in the outcomes of peripheral arterial disease: a population-based cohort study
}

\author{
Mohamad A. Hussain MD, Thomas F. Lindsay MDCM MSc, Muhammad Mamdani PharmD MPH, \\ Xuesong Wang MSc, Subodh Verma MD PhD, Mohammed Al-Omran MD MSc
}

\section{Abstract}

Background: The role of sex in the outcomes of patients with peripheral arterial disease (PAD) has been poorly studied. We sought to investigate differences in the long-term adverse cardiovascular and limb outcomes between men and women with PAD.

Methods: We conducted a population-based cohort study with up to 7 years of follow-up using linked administrative databases in Ontario, Canada. Patients aged 40 years or older who visited a vascular surgeon between Apr. 1, 2004, and Mar. 31, 2007 (index date), and carried a diagnosis of PAD comprised the study cohort. The primary outcome was a composite of death or hospital admission for stroke or myocardial infarction. Secondary outcomes included lower limb amputation or revascularization. We used Cox proportional hazards modelling to compute unadjusted hazard ratios (HRs) and HRs adjusted for baseline covariates.

Results: A total of 6915 patients were studied, of whom $2461(35.6 \%)$ were women. No significant differences in the risk of the primary outcome were observed between men and women (adjusted HR 0.99 [95\% confidence interval (Cl) 0.92-1.05]). Women were less likely than men to undergo minor amputation (adjusted HR 0.73 [95\% Cl 0.62-0.85]) and arterial bypass surgery (adjusted HR $0.82[95 \% \mathrm{Cl} 0.71-0.94]$ ) but were more likely to be admitted to hospital for acute myocardial infarction (adjusted $\mathrm{HR} 1.15$ [95\% $\mathrm{Cl}$ 1.00-1.31]). There were no sex differences in the rates of major amputation or transluminal percutaneous angioplasty.

Interpretation: We identified no significant differences in the composite risk of major adverse cardiovascular events between women and men with PAD, although our findings suggest men may be at increased risk for adverse limb events compared with women. Cardiovascular health campaigns should focus on both women and men to promote early diagnosis and management of PAD.

$\mathrm{P}$ eripheral arterial disease (PAD) is the third most common cause of death from cardiovascular disorders, after coronary heart disease and stroke. There has been a rapid increase in the number of people with PAD over the last decade, with about 202 million people with the disease globally in 2010. ${ }^{1}$ Data from the Global Burden of Disease projects in 1990 and 2010 showed that, although men have an overall greater burden of PAD, women experienced a much more dramatic increase in PAD-related death and disability over that period than did men. ${ }^{2}$ Despite this, PAD is not currently a focus in national cardiovascular health programs for men and women in Canada. ${ }^{3}$

Sex-based differences in the clinical presentation and outcomes of men and women with other vascular diseases such as coronary heart disease are well documented, ${ }^{4-6}$ and several national initiatives have been established to tackle these differences in health care. Differences between women and men in the etiology and clinical presentation of PAD have also been suggested. ${ }^{7}$ However, long-term data on sex-based differences in the cardiovascular and limb outcomes of patients with PAD are limited. Previous population-based studies have focused primarily on postoperative in-hospital outcomes, and their findings have been conflicting. ${ }^{8-10}$ In a Scientific Statement published in 2012, the American Heart Association noted that "cardiovascular mortality, all-cause mortality, and major coronary event rates by gender have not been well defined in population-based studies." 11

To address this gap in knowledge, we conducted a large population-based cohort study to examine differences in rates of major adverse cardiovascular and limb events between

Competing interests: None declared.

This article has been peer reviewed.

Correspondence to: Mohammed Al-Omran, AlomranM@smh.ca

CMAJ Open 2016. DOI:10.9778/cmajo.20150107 
women and men with PAD over the long-term. We hypothesized that women with PAD may be at increased risk for adverse cardiovascular events compared with men even after any differences in baseline characteristics are controlled for.

\section{Methods}

\section{Setting}

We designed a retrospective population-based cohort study of men and women with PAD using linked health care administrative databases in Ontario from Apr. 1, 2004, to Mar. 31, 2013. Over 13 million Ontario residents have access to universal health care services funded by the Ministry of Health and Long-Term Care.

\section{Data sources}

We used the following linked Ontario administrative data sets to conduct this study: the Canadian Institute for Health Information Discharge Abstract Database (captures all hospital admission information, including diagnoses and procedures), the Ontario Health Insurance Plan Database (data from all inpatient and outpatient physician billing claims), the Registered Persons Database (demographic and vital statistics data), the National Ambulatory Care Reporting System (data from outpatient surgical procedures and emergency department visits), the Institute for Clinical Evaluative Sciences Physicians Database (demographic and specialty information about all physicians practising in Ontario) and the Ontario Drug Benefit database (data from medication prescriptions dispensed to Ontario residents aged 65 years or older). These databases have shown to be of high quality, ${ }^{12}$ have been validated for identifying a variety of diagnoses and procedures ${ }^{13-16}$ and are routinely used for population-based outcome studies. ${ }^{17-19}$

\section{Patients}

All men and women who were seen by a vascular surgeon in Ontario between Apr. 1, 2004, and Mar. 31, 2007, and who had a diagnosis of PAD within 3 years before that visit were considered eligible for the study. We defined the diagnosis of PAD using a validated model-based billing code algorithm that has been shown to be accurate in identifying patients with $\mathrm{PAD}$ in the noninvasive vascular laboratory and the community. ${ }^{20}$ Details of the billing code algorithm and the codes of the International Classification of Diseases, 9th and 10th editions, used to identify patients with $\mathrm{PAD}$ can be found in Appendix 1, available at www.cmajopen.ca/content/4/1/E124/ suppl/DC1. To restrict the analysis to patients with atherosclerotic disease, we excluded patients who were less than 40 years old.

\section{Outcome measures and follow-up}

The primary outcome was a composite of death or hospital admission for acute myocardial infarction or stroke. Each individual component outcome of the primary outcome was examined as a secondary outcome. We also examined the following limb outcomes as secondary outcomes: major amputation (level of ankle, below-knee or above-knee), minor ampu- tation (toe or through-foot), peripheral arterial bypass surgery and percutaneous transluminal angioplasty. Hospital admission for congestive heart failure, carotid endarterectomy, abdominal aortic aneurysm repair, coronary revascularization or initiation of dialysis was measured as a tertiary outcome. Follow-up was started on the day the patient had a clinical encounter with a vascular surgeon (cohort entry date). Patients were followed until they experienced the primary outcome or reached the maximum follow-up period of 7 years, or until the end of the study (Mar. 31, 2013).

\section{Covariates}

We controlled for confounding factors that might influence the effect of sex on adverse cardiovascular outcomes by using various linked administrative data sets. These factors included patient age, income level, medical comorbidities and overall comorbidity burden, medication use and use of health care services (including hospital admissions, emergency department visits and outpatient physician visits). We estimated income level by linking the patient's home postal code to population census data from Statistics Canada to obtain the median household income quintile. ${ }^{21} \mathrm{We}$ estimated overall comorbidity burden using the Charlson Comorbidity Index with a 1-year look-back window in the data sets. This comorbidity index has been validated to predict the probability of death from comorbid disease in patients with PAD and aortic disease. ${ }^{22}$ In general, the risk of death from an increase of 1 Charlson Comorbidity Index score is equivalent to the risk of death from an additional decade of age. ${ }^{22}$ In addition, we controlled for patient ambulatory care grouping using the Comprehensive Ambulatory Classification System. This national classification system places patient visits into groups that are homogeneous both clinically and in terms of resource use. It can be used to further predict patient comorbidity burden and use of health care resources. ${ }^{23} \mathrm{We}$ controlled for baseline medication use by determining the medication prescriptions dispensed to patients using the Ontario Drug Benefit database. ${ }^{12}$ Details of codes used to define covariates and outcomes are outlined in Appendix 2, available at www.cmajopen.ca/content/4/1/E124/suppl/DC1.

\section{Statistical analysis}

We used standardized differences to compare male and female patients' baseline demographic and clinical characteristics. Standardized differences of less than 0.1 generally indicate good balance. ${ }^{24}$

We performed time-to-event analyses using multivariable Cox proportional hazards regression (PROC PHREG in SAS, version 9.4) to compare outcomes of men and women, with men as the reference group. We generated unadjusted hazard ratios (HRs) and HRs adjusted for baseline demographic and clinical variables. We also calculated adjusted event rates per 1000 person-years for each outcome. We tested the proportional hazards assumption by visually inspecting log-log survival curves and by examining the statistical significance of time-dependent covariates. We also generated adjusted Kaplan-Meier curves with $95 \%$ confidence intervals (CIs) to 
Table 1: Baseline demographic and clinical characteristics of patients with peripheral arterial disease

\begin{tabular}{|c|c|c|c|}
\hline Characteristic & Men $(n=4454)$ & Women $(n=2461)$ & Standardized difference* \\
\hline Age, yr, mean \pm SD & $68.7 \pm 10.6$ & $71.6 \pm 11.5$ & 0.27 \\
\hline \multicolumn{4}{|l|}{ Charlson Comorbidity Index score, no. (\%)† } \\
\hline 0 & $219(4.9)$ & $133(5.4)$ & 0.02 \\
\hline 1 & $953(21.4)$ & $619(25.2)$ & 0.09 \\
\hline$\geq 2$ & $2735(61.4)$ & $1384(56.2)$ & 0.11 \\
\hline \multicolumn{4}{|l|}{ Neighbourhood income quintile, no. (\%)† } \\
\hline 1 (lowest) & $1149(25.8)$ & $641(26.0)$ & 0.01 \\
\hline 2 & $986(22.1)$ & $593(24.1)$ & 0.05 \\
\hline 3 & $833(18.7)$ & $432(17.6)$ & 0.03 \\
\hline 4 & $759(17.0)$ & $423(17.2)$ & 0.00 \\
\hline 5 (highest) & $705(15.8)$ & $353(14.3)$ & 0.04 \\
\hline \multicolumn{4}{|l|}{ Ambulatory care group, no. (\%)† } \\
\hline Nervous system diseases & $122(2.7)$ & $61(2.5)$ & 0.02 \\
\hline Eye diseases & $7(0.2)$ & $\leq 5 \ddagger$ & 0.01 \\
\hline Ear, nose, mouth and throat diseases & $34(0.8)$ & $23(0.9)$ & 0.02 \\
\hline Respiratory diseases & $113(2.5)$ & $77(3.1)$ & 0.04 \\
\hline Circulatory system diseases & $885(19.9)$ & $525(21.3)$ & 0.04 \\
\hline Digestive system diseases & $135(3.0)$ & $108(4.4)$ & 0.07 \\
\hline Hepatobiliary and pancreatic diseases & $24(0.5)$ & $6(0.2)$ & 0.04 \\
\hline Musculoskeletal and connective tissue diseases & $181(4.1)$ & $117(4.8)$ & 0.03 \\
\hline Skin, subcutaneous tissue and breast diseases & $418(9.4)$ & $239(9.7)$ & 0.01 \\
\hline Endocrine, nutritional and metabolic diseases & $325(7.3)$ & $126(5.1)$ & 0.09 \\
\hline Kidney and genitourinary tract diseases & $297(6.7)$ & $148(6.0)$ & 0.03 \\
\hline Hematological diseases & $26(0.6)$ & $17(0.7)$ & 0.01 \\
\hline Oncological diseases & $37(0.8)$ & $7(0.3)$ & 0.07 \\
\hline Systematic infections & $34(0.8)$ & $8(0.3)$ & 0.06 \\
\hline Mental diseases & $18(0.4)$ & $13(0.5)$ & 0.02 \\
\hline Examination and other health factors & $384(8.6)$ & $191(7.8)$ & 0.03 \\
\hline Trauma, coma and toxic effects & $258(5.8)$ & $147(6.0)$ & 0.01 \\
\hline \multicolumn{4}{|l|}{ Health service use } \\
\hline No. of outpatient physician visits in past yr, mean \pm SD & $17.0 \pm 11.1$ & $16.6 \pm 10.2$ & 0.04 \\
\hline No. of emergency department visits in past $3 \mathrm{yr}$, mean \pm SD & $3.9 \pm 5.3$ & $4.0 \pm 5.1$ & 0.01 \\
\hline No. of hospital admissions in past $3 \mathrm{yr}$, mean \pm SD & $2.8 \pm 2.3$ & $2.8 \pm 2.2$ & 0.01 \\
\hline Medications, no. (\%)§ & $n=2810$ & $n=1742$ & \\
\hline Orally administered antihyperglycemic & $798(28.4)$ & $382(21.9)$ & 0.15 \\
\hline Insulin & $505(18.0)$ & $263(15.1)$ & 0.08 \\
\hline Statin & $1715(61.0)$ & $949(54.5)$ & 0.13 \\
\hline$\beta$-Blocker & $1403(49.9)$ & $838(48.1)$ & 0.04 \\
\hline Calcium-channel blocker & $1086(38.6)$ & $831(47.7)$ & 0.18 \\
\hline ACE inhibitor or ARB & $1999(71.1)$ & $1206(69.2)$ & 0.04 \\
\hline Diuretic & $1017(36.2)$ & $701(40.2)$ & 0.08 \\
\hline Any antihypertensive & $2470(87.9)$ & $1545(88.7)$ & 0.02 \\
\hline Clopidogrel & $348(12.4)$ & $198(11.4)$ & 0.03 \\
\hline Acetylsalicylic acid & $604(21.5)$ & $365(21.0)$ & 0.01 \\
\hline Warfarin & $719(25.6)$ & $372(21.4)$ & 0.10 \\
\hline \multicolumn{4}{|l|}{ Comorbid conditions, no. (\%) } \\
\hline Congestive heart failure & $721(16.2)$ & $388(15.8)$ & 0.01 \\
\hline Stroke & $180(4.0)$ & $98(4.0)$ & 0.00 \\
\hline Acute myocardial infarction & $564(12.7)$ & $250(10.2)$ & 0.08 \\
\hline Coronary artery disease & $1173(26.3)$ & $495(20.1)$ & 0.15 \\
\hline Chronic obstructive pulmonary disease & $359(8.1)$ & $240(9.8)$ & 0.06 \\
\hline Chronic kidney disease & $871(19.6)$ & $403(16.4)$ & 0.08 \\
\hline Diabetes mellitus & $1694(38.0)$ & $776(31.5)$ & 0.14 \\
\hline \multicolumn{4}{|c|}{$\begin{array}{l}\text { Note: } \mathrm{ACE}=\text { angiotensin-converting enzyme, } \mathrm{ARB}=\text { angiotensin-receptor blocker. } \\
\text { *Standardized difference of }>0.1 \text { indicates significant difference. } \\
\text { †Missing values: Charlson Comorbidity Index } 547 \text { men }(12.3 \%), 325 \text { women }(13.2 \%) \text {; neighbourhood income quintile } 22 \text { men }(0.5 \%), 19 \text { women }(0.8 \%) \text {; ambulatory care } \\
\text { group } 1156 \text { men }(26.0 \%), 643 \text { women ( } 26.1 \%) . \\
\text { tCells containing } \leq 5 \text { observations are suppressed. } \\
\text { §Medication use is reported only for those aged } 66 \text { years or older. }\end{array}$} \\
\hline
\end{tabular}


demonstrate the cumulative incidence of primary and secondary outcomes.

All statistical analyses were conducted with the use of SAS, version 9.4.

Ethical approval for this study was obtained from the Institute for Clinical Evaluative Sciences, and the need for individual patient consent was waived.

\section{Results}

A total of 6915 patients with PAD were included in our analysis. Of these patients, 2461 (35.6\%) were women. The median duration of follow-up for the cohort was 5.4 years (interquartile range $1.8-7$ years).

\section{Baseline characteristics}

Women with PAD were more likely than their male counterparts to be older ( 72 v. 69 years) (Table 1). Men were more likely than women to have a history of coronary artery disease or diabetes mellitus, and they tended to have a higher Charlson Comorbidity Index score, indicating a greater comorbidity burden. Men were also prescribed orally administered antihyperglycemic agents and statins at higher rates than women, whereas women were prescribed calcium-channel blockers at a higher rate than men. Analysis of baseline income quintile, use of health care services and clinical encounters based on 17 unique ambulatory care groupings showed no significant differences between women and men.

\section{Primary outcome}

The primary outcome (composite of death or hospital admission for acute myocardial infarction or stroke) occurred in 2860 men $(64.2 \%)$ and 1644 women (66.8\%). Women experienced the primary outcome at a higher rate in the unadjusted model (unadjusted HR 1.06 [95\% CI $1.00-1.13]$ ), but this difference disappeared after baseline covariates were controlled for (adjusted HR 0.99 [95\% CI 0.92-1.05]) (Table 2). The cumulative incidence of the primary outcome over follow-up is presented in Figure 1.

\section{Secondary and tertiary outcomes}

Women were less likely than men to undergo minor amputation (adjusted HR 0.73 [95\% CI 0.62-0.85]) and arterial bypass surgery (adjusted HR 0.82 [95\% CI 0.71-0.94]) but were more likely to be admitted to hospital for acute myocardial infarction (adjusted HR 1.15 [95\% CI 1.00-1.31]) (Table 2). There were no differences in the rates of major amputation, percutaneous transluminal angioplasty, stroke or death between women and men. The cumulative incidences of secondary limb outcomes are presented in Figures 2 and 3. In addition, there were no significant differences in any of the tertiary outcomes between men and women in the adjusted models.

\section{Interpretation}

In this large population-based cohort study, we found no statistically significant differences between women and men with

Table 2: Outcomes by sex

\begin{tabular}{|c|c|c|c|c|c|c|}
\hline \multirow[b]{2}{*}{ Outcome } & \multirow{2}{*}{$\begin{array}{c}\text { Men, } \\
\text { no. }(\%) \\
(n=4454)\end{array}$} & \multirow{2}{*}{$\begin{array}{c}\text { Women, } \\
\text { no. }(\%) \\
(n=2461)\end{array}$} & \multirow{2}{*}{$\begin{array}{l}\text { Unadjusted HR } \\
(95 \% \mathrm{Cl})\end{array}$} & \multirow{2}{*}{$\begin{array}{l}\text { Adjusted } \mathrm{HR}^{\star} \\
\qquad(95 \% \mathrm{Cl})\end{array}$} & \multicolumn{2}{|c|}{$\begin{array}{l}\text { Adjusted event rate per } \\
1000 \text { person-years }\end{array}$} \\
\hline & & & & & Men & Women \\
\hline Primary outcome & $2860(64.2)$ & $1644(66.8)$ & $1.06(1.00-1.13)$ & $0.99(0.92-1.05)$ & 162.6 & 159.4 \\
\hline \multicolumn{7}{|l|}{ Secondary outcome } \\
\hline Acute myocardial infarction & $618(13.9)$ & $360(14.6)$ & $1.07(0.94-1.22)$ & $1.15(1.00-1.31)$ & 30.1 & 34.5 \\
\hline Stroke & $229(5.1)$ & $140(5.7)$ & $1.13(0.92-1.40)$ & $1.02(0.82-1.27)$ & 9.6 & 9.7 \\
\hline Death & $2562(57.5)$ & $1468(59.6)$ & $1.06(0.99-1.13)$ & $0.96(0.90-1.03)$ & 130.0 & 124.1 \\
\hline Major amputation & 764 (17.2) & $375(15.2)$ & $0.89(0.79-1.01)$ & $0.95(0.84-1.08)$ & 38.3 & 36.2 \\
\hline Minor amputation & $583(13.1)$ & $211(8.6)$ & $0.65(0.55-0.76)$ & $0.73(0.62-0.85)$ & 23.8 & 16.9 \\
\hline Arterial bypass surgery & $685(15.4)$ & $311(12.6)$ & $0.82(0.72-0.94)$ & $0.82(0.71-0.94)$ & 39.2 & 31.5 \\
\hline PCTA & $609(13.7)$ & $330(13.4)$ & $0.99(0.87-1.14)$ & $1.04(0.90-1.19)$ & 33.0 & 34.1 \\
\hline \multicolumn{7}{|l|}{ Tertiary outcome } \\
\hline Congestive heart failure & $1144(25.7)$ & $623(25.3)$ & $1.01(0.92-1.11)$ & $1.01(0.91-1.12)$ & 60.9 & 61.4 \\
\hline Carotid endarterectomy & $82(1.8)$ & $34(1.4)$ & $0.76(0.51-1.14)$ & $0.77(0.50-1.12)$ & 0.4 & 0.3 \\
\hline Abdominal aortic aneurysm repair & $271(6.1)$ & $126(5.1)$ & $0.85(0.69-1.05)$ & $0.92(0.74-1.15)$ & 9.1 & 8.3 \\
\hline Coronary revascularization & $442(9.9)$ & $187(7.6)$ & $0.77(0.65-0.91)$ & $0.85(0.71-1.02)$ & 18.2 & 15.5 \\
\hline Initiation of dialysis & $749(16.8)$ & $322(13.1)$ & $0.77(0.68-0.88)$ & $0.89(0.78-1.03)$ & 21.4 & 18.2 \\
\hline
\end{tabular}




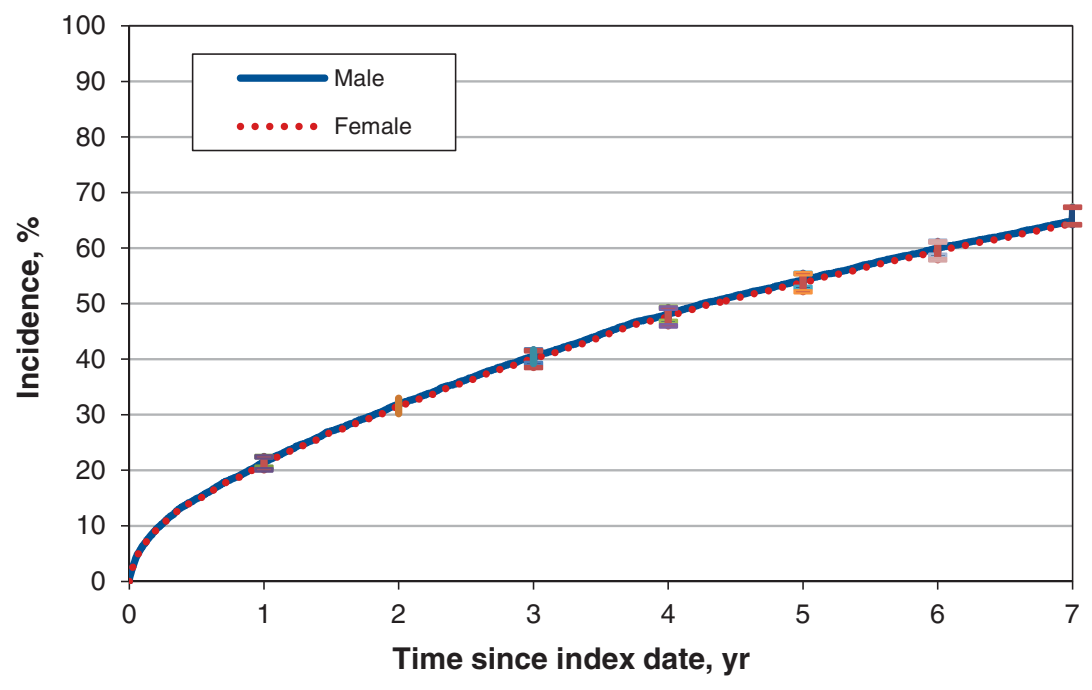

Figure 1: Incidence over follow-up of primary outcome (death or hospital admission for acute myocardial infarction or stroke), adjusted for patient age, income level, medical comorbidities and overall comorbidity burden, medication use, use of health care services (including hospital admissions, emergency department visits and outpatient physician visits) and ambulatory care group classification. Error bars represent $95 \%$ confidence intervals.
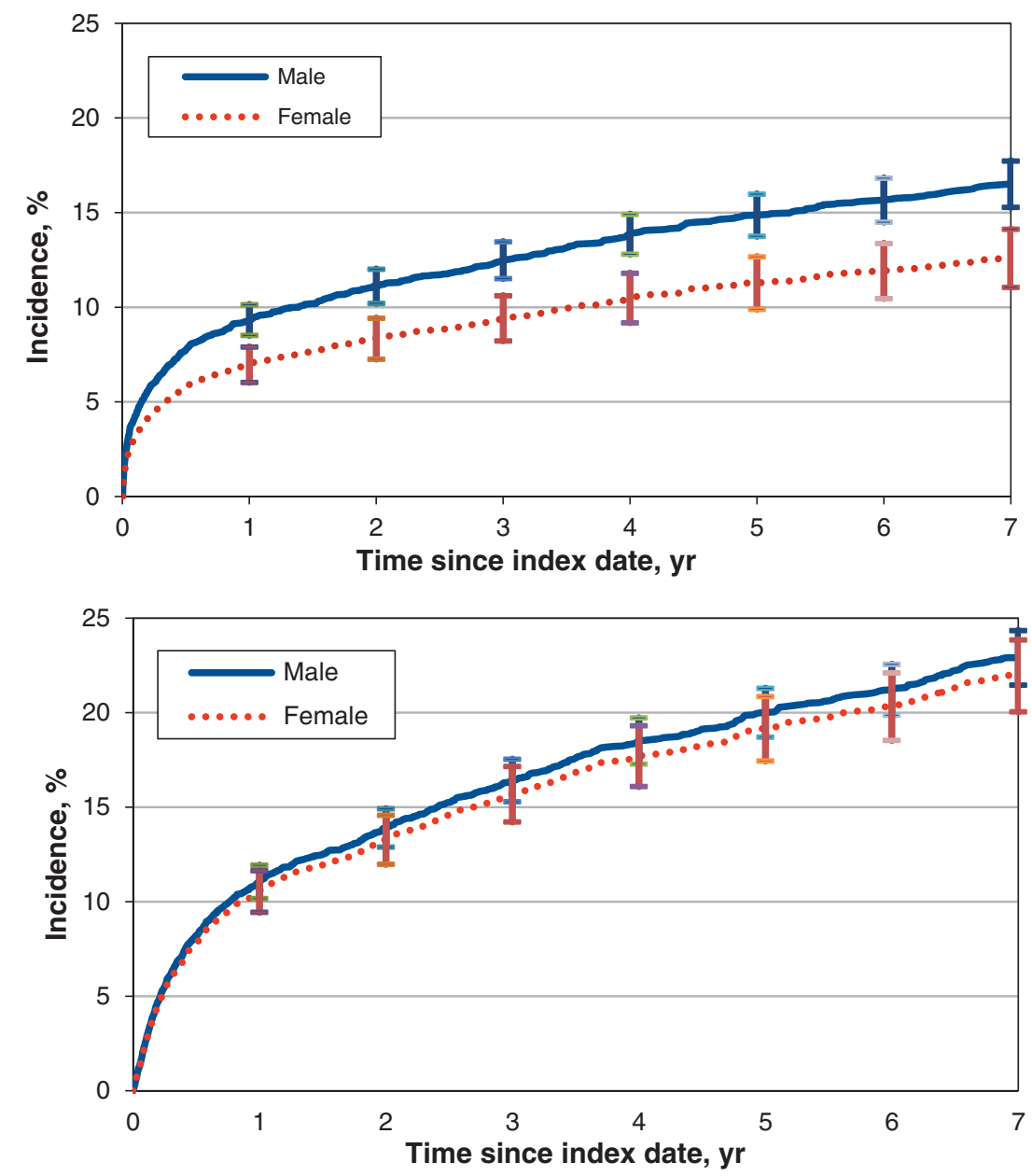

Figure 2: Incidence over follow-up of minor amputation (top) and major amputation (bottom), adjusted for patient age, income level, medical comorbidities and overall comorbidity burden, medication use, use of health care services (including hospital admissions, emergency department visits and outpatient physician visits) and ambulatory care group classification. Error bars represent $95 \%$ confidence intervals. 

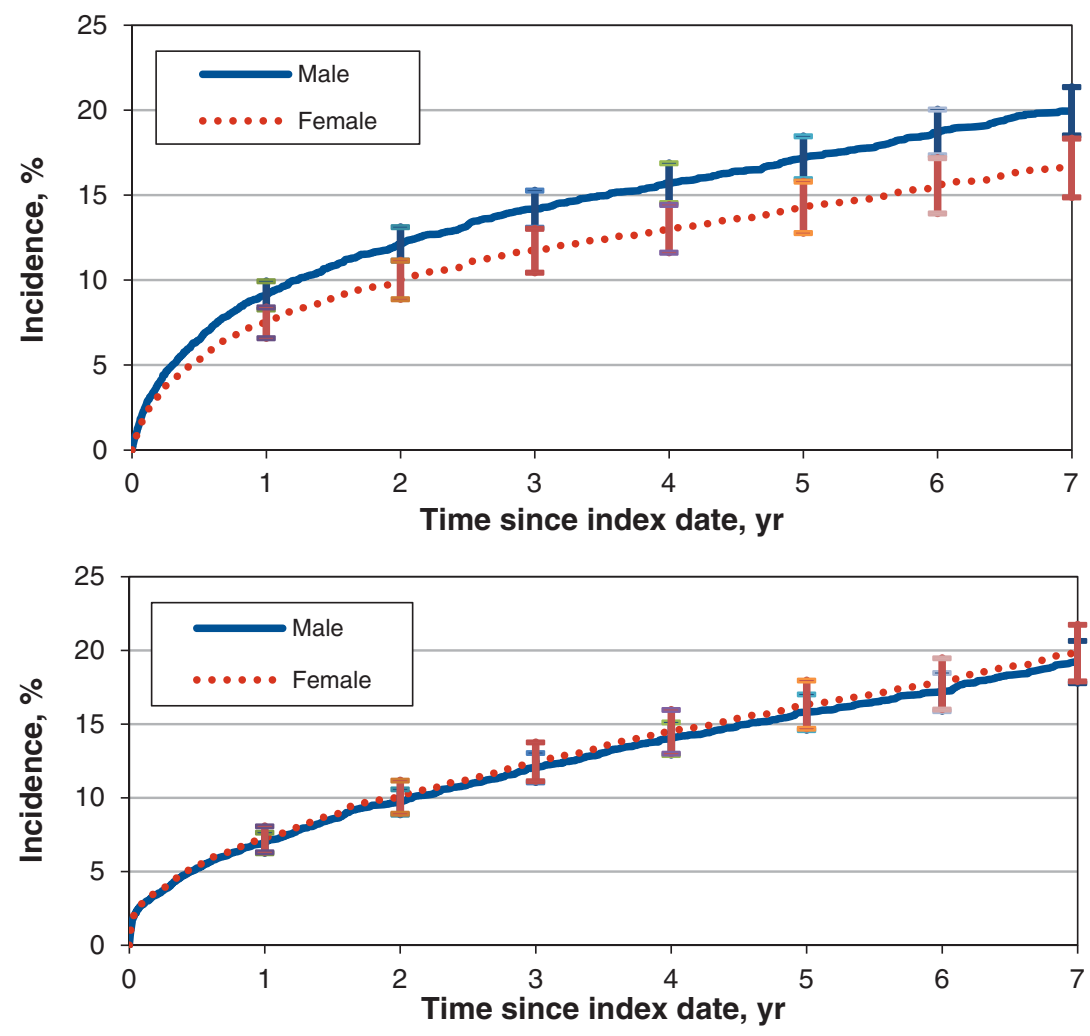

Figure 3: Incidence over follow-up of arterial bypass surgery (top) and percutaneous transluminal angioplasty (bottom), adjusted for patient age, income level, medical comorbidities and overall comorbidity burden, medication use, use of health care services (including hospital admissions, emergency department visits and outpatient physician visits) and ambulatory care group classification. Error bars represent $95 \%$ confidence intervals.

respect to a composite risk of acute myocardial infarction, stroke or death. Secondary analyses showed that female sex was associated with a higher risk of hospital admission due to myocardial infarction but a lower risk of minor amputation and arterial bypass surgery.

The findings of prior studies examining sex-related differences in the outcomes of patients with PAD following peripheral arterial procedures have been conflicting. Jackson and colleagues $^{8}$ recently reported data for 12379 patients $(41 \%$ female) who underwent peripheral vascular interventions. Although women experienced more procedure-related complications, the rates of myocardial infarction, stroke, death and amputation did not differ between women and men. However, the study was limited to in-hospital postprocedure follow-up. In contrast, Vouyouka and colleagues ${ }^{9}$ analyzed population-based data from 372692 PAD-related surgical hospital admissions (44\% involving women) and reported a higher risk of postoperative complications, major amputation and death among women even after adjusting for baseline covariates. That study was also limited by a lack of longitudinal follow-up after discharge, and only patients undergoing peripheral arterial revascularization or amputation procedures were enrolled. Recent data from the US Nationwide Inpatient Sample suggest that women who undergo interventions for PAD have higher rates of in-hospital death than do men, although the rates for both sexes have declined over time, likely owing to improvements in technology and medical therapy. ${ }^{10}$ The authors measured no other clinical outcomes owing to a limitation of the administrative databases.

Our study has several strengths that provide insight into the influence of sex on PAD outcomes. First, unlike prior studies, the index event in our study cohort was not a surgical intervention for PAD but, rather, a clinical encounter with a vascular surgeon and a prior diagnosis of PAD. This approach allowed us to include inpatients and outpatients with varying levels of disease severity in our cohort. Prior studies focused on patients with advanced PAD (critical limb ischemia or debilitating intermittent claudication) undergoing peripheral arterial interventions. ${ }^{8-10,25,26}$ Findings from our study may be more generalizable because we included a broader range of patients. Second, our study provides robust long-term data (median follow-up duration 5.4 years), whereas prior population-based studies focused largely on in-hospital outcomes in this population. Third, we adjusted for several factors that may confound the relationship between sex and PAD outcomes, such as socioeconomic status, use of health care services, ambulatory care grouping and overall comorbidity burden. These factors play an important role in access to care and have not been measured in prior studies examining sex-related differences in PAD. Finally, our study provides insight into characteristics of patients with $\mathrm{PAD}$ that have not been previously described. For instance, we found that about $50 \%$ of 
men and women with PAD belonged to the lowest 2 income quintiles. Given that socioeconomic class is closely associated with health status, ${ }^{27}$ our data indicate further investigation is warranted to determine the impact of lower socioeconomic status on the health outcomes of patients with PAD.

In our cohort, women with PAD tended to be older than men with the disease, which is consistent with data from other studies. ${ }^{8-10,25}$ This may be because women are more likely to experience atypical symptoms that are not characteristic of a classical history of intermittent claudication, thus leading to a delay in PAD diagnosis. ${ }^{28,29}$ Furthermore, women with PAD had more advanced disease at the time of presentation, as evidenced by a greater incidence of critical limb ischemia ${ }^{30,31}$ and faster functional decline. ${ }^{32}$ Although these clinical findings can be explained by advanced age, other factors, such as an enhanced proinflammatory state, ${ }^{33}$ impaired microvascular function $^{34}$ and greater burden of femoropopliteal lesions, ${ }^{35}$ observed in women with PAD may also contribute to more advanced disease compared with that in men.

Although women were at increased risk for acute myocardial infarction, stroke or death in the unadjusted analysis, we found no differences among women and men after adjusting for age and other covariates. This further indicates the importance of early diagnosis and treatment of PAD in women. We did, however, find 2 key differences between men and women in our secondary analyses that merit discussion. First, we found that women were less likely than men to undergo minor amputation and arterial bypass surgery. This may be because men were observed to have a greater comorbidity burden at baseline, including a prior history of diabetes mellitus, which is a significant risk factor for advanced atherosclerosis and amputation. ${ }^{19}$ Second, we found that women were at increased risk for acute myocardial infarction in the adjusted analysis. Given that women in our study were on average 3 years older than men, this finding is consistent with previous research indicating that women experience acute myocardial infarction at an older age than men. ${ }^{36}$ However, the possibility also exists that a lower rate of peripheral arterial interventions signifies that women with PAD may be inappropriately undertreated with minor amputation and bypass surgery compared with men; we were not able to confirm this owing to a lack of data about severity of PAD in our databases. We found no significant differences between women and men in the adjusted rates of stroke, death, major amputation, percutaneous transluminal angioplasty or any of the tertiary outcomes.

\section{Limitations}

Our study has several limitations. First, as with all observational studies, our results may be biased by unmeasured differences between men and women, such as body mass index, smoking history, blood pressure, blood lipid values and exercise level. However, we measured several demographic and clinical covariates at baseline, and we also adjusted our analyses for variables that may confound the relationship between sex and PAD outcomes. Second, inaccurate coding is a possible source of bias in population-based studies. To mitigate this risk, we used codes that had already been validated in our databases to identify patients with PAD and their outcomes. The model-based billing code algorithm has good accuracy (86\% sensitivity, 83\% specificity, 91\% positive predictive value, $74 \%$ negative predictive value) in identifying patients with PAD. ${ }^{20}$ Coding for the major cardiovascular and limb outcomes of interest, including acute myocardial infarction ( $83 \%$ sensitivity, $87 \%$ positive predictive value), stroke $(81 \%$ accuracy), arterial bypass surgery ( $87 \%$ sensitivity, $88 \%$ positive predictive value) and major amputation (98\% sensitivity, 96\% positive predictive value), has also been validated in our databases through reabstraction studies. ${ }^{37}$ Finally, our databases did not allow us to determine the severity of PAD symptoms in our cohort. However, by including patients who had a clinical encounter with a vascular surgeon, we are confident that our cohort represents a broad $\mathrm{PAD}$ population with varying severity of disease that is managed by vascular specialists.

\section{Conclusion}

Our results suggest that, although women with PAD tend to be older than their male counterparts, no sex-based differences exist in the long-term composite risk of acute myocardial infarction, stroke or death in patients with PAD after baseline risk factors are controlled for. Men with PAD tend to have a higher comorbidity burden than women with the disease, and they may be at increased risk for adverse limb events. Our results highlight the need to target both women and men in cardiovascular health campaigns to promote early diagnosis and management of PAD. Formal research into the development and implementation of such programs is warranted.

\section{References}

1. Fowkes FGR, Rudan D, Rudan I, et al. Comparison of global estimates of prevalence and risk factors for peripheral artery disease in 2000 and 2010: a systematic review and analysis. Lancet 2013;382:1329-40.

2. Sampson UKA, Fowkes FGR, McDermott MM, et al. Global and regional burden of death and disability from peripheral artery disease: 21 world regions, 1990 to 2010. Glob Heart 2014;9:145-58.e21

3. Lovell M, Harris K, Forbes T, et al. Peripheral arterial disease: lack of awareness in Canada. Can 7 Cardiol 2009;25:39-45.

4. Vaccarino V, Rathore SS, Wenger NK, et al. Sex and racial differences in the management of acute myocardial infarction, 1994 through 2002. N Engl 7 Med 2005;353:671-82.

5. Berger JS, Elliott L, Gallup D, et al. Sex differences in mortality following acute coronary syndromes. $\mathcal{F} A M A$ 2009;302:874-82.

6. Canto JG, Rogers WJ, Goldberg RJ, et al. Association of age and sex with myocardial infarction symptom presentation and in-hospital mortality. 7AMA 2012;307:813-22.

7. Barochiner J, Aparicio LS, Waisman GD. Challenges associated with peripheral arterial disease in women. Vasc Health Risk Manag 2014;10:115-28.

8. Jackson EA, Munir K, Schreiber T, et al. Impact of sex on morbidity and mortality rates after lower extremity interventions for peripheral arterial disease: observations from the Blue Cross Blue Shield of Michigan Cardiovascular Consortium. 7 Am Coll Cardiol 2014;63:2525-30.

9. Vouyouka AG, Egorova NN, Salloum A, et al. Lessons learned from the analysis of gender effect on risk factors and procedural outcomes of lower extremity arterial disease. 7 Vasc Surg 2010;52:1196-202.

10. Lo RC, Bensley RP, Dahlberg SE, et al. Presentation, treatment, and outcome differences between men and women undergoing revascularization or amputation for lower extremity peripheral arterial disease. 7 Vasc Surg 2014;59:409-418.e3

11. Hirsch AT, Allison MA, Gomes AS, et al. A call to action: women and peripheral artery disease: a scientific statement from the American Heart Association. Circulation 2012;125:1449-72.

12. Levy AR, O'Brien BJ, Sellors C, et al. Coding accuracy of administrative drug claims in the Ontario Drug Benefit database. Can 7 Clin Pharmacol 2003;10:67-71.

13. Austin PC, Daly PA, Tu JV. A multicenter study of the coding accuracy of hospital discharge administrative data for patients admitted to cardiac care units in Ontario. Am Heart 7 2002;144:290-6. 
14. Kokotailo RA, Hill MD. Coding of stroke and stroke risk factors using International Classification of Diseases, revisions 9 and 10. Stroke 2005;36:1776-81.

15. Lee DS, Stitt A, Wang X, et al. Administrative hospitalization database validation of cardiac procedure codes. Med Care 2013;51:e22-6.

16. Hux JE, Ivis F, Flintoft V, et al. Diabetes in Ontario: determination of prevalence and incidence using a validated administrative data algorithm. Diabetes Care 2002;25:512-6.

17. Dhalla IA, Gomes T, Yao Z, et al. Chlorthalidone versus hydrochlorothiazide for the treatment of hypertension in older adults: a population-based cohort study. Ann Intern Med 2013;158:447-55.

18. Park-Wyllie LY, Juurlink DN, Kopp A, et al. Outpatient gatifloxacin therapy and dysglycemia in older adults. N Engl 7 Med 2006;354:1352-61.

19. Al-Omran M, Tu JV, Johnston KW, et al. Outcome of revascularization procedures for peripheral arterial occlusive disease in Ontario between 1991 and 1998: a population-based study. 7 Vasc Surg 2003;38:279-88.

20. Fan J, Arruda-Olson AM, Leibson CL, et al. Billing code algorithms to identify cases of peripheral artery disease from administrative data. $7 \mathrm{Am} \mathrm{Med}$ Inform Assoc 2013;20:e349-54

21. Glazier RH, Creatore MI, Agha MM, et al. Socioeconomic misclassification in Ontario's Health Care Registry. Can 7 Public Health 2003;94:140-3.

22. Charlson M, Szatrowski TP, Peterson J, et al. Validation of a combined comorbidity index. 7 Clin Epidemiol 1994;47:1245-51.

23. Starfield B, Weiner J, Mumford L, et al. Ambulatory care groups: a categorization of diagnoses for research and management. Health Serv Res 1991;26: 53-74.

24. Austin PC. Using the standardized difference to compare the prevalence of a binary variable between two groups in observational research. Commun Stat Simul Comput 2009;38:1228-34.

25. Wisman PP, Tangelder MJ, van Hattum ES, et al. Young women with PAD are at high risk of cardiovascular complications. Eur $\mathcal{7}$ Vasc Endovasc Surg 2012;43:441-5

26. Abando A, Akopian G, Katz SG. Patient sex and success of peripheral percutaneous transluminal arterial angioplasty. Arch Surg 2005;140:757-61.

27. Isaacs SL, Schroeder SA. Class - the ignored determinant of the nation's health. NEngl 7 Med 2004;351:1137-42.

28. Sigvant B, Lundin F, Nilsson B, et al. Differences in presentation of symptoms between women and men with intermittent claudication. BMC Cardiovasc Disord 2011:11:39.

29. McDermott MM, Greenland P, Liu K, et al. Sex differences in peripheral arterial disease: leg symptoms and physical functioning. 7 Am Geriatr Soc 2003;51:222-8.

30. Kumakura H, Kanai H, Araki Y, et al. Sex-related differences in Japanese patients with peripheral arterial disease. Atherosclerosis 2011;219:846-50.

31. Sigvant B, Wiberg-Hedman K, Bergqvist D, et al. A population-based study of peripheral arterial disease prevalence with special focus on critical limb ischemia and sex differences. F Vasc Surg 2007;45:1185-91.

32. McDermott MM, Ferrucci L, Liu K, et al. Women with peripheral arterial disease experience faster functional decline than men with peripheral arterial disease. 7 Am Coll Cardiol 2011;57:707-14

33. Gardner AW, Parker DE, Montgomery PS, et al. Gender and racial differences in endothelial oxidative stress and inflammation in patients with symptomatic peripheral artery disease. 7 Vasc Surg 2015;61:1249-57.

34. Gardner AW, Montgomery PS, Blevins SM, et al. Gender and ethnic differences in arterial compliance in patients with intermittent claudication. 7 Vasc Surg 2010;51:610-5.
35. Ortmann J, Nüesch E, Traupe T, et al. Gender is an independent risk factor for distribution pattern and lesion morphology in chronic critical limb ischemia. 7 Vasc Surg 2012;55:98-104.

36. Anand SS, Islam S, Rosengren A, et al. Risk factors for myocardial infarction in women and men: insights from the INTERHEART study. Eur Heart 7 2008;29:932-40.

37. Juurlink DN, Preyra C, Coxford R, et al. Canadian Institute for Health Information discharge abstract database: a validation study. Toronto: Institute for Clinical Evaluative Sciences; 2006.

Affiliations: Divisions of Vascular Surgery (Hussain, Al-Omran) and Cardiac Surgery (Verma), St. Michael's Hospital; Li Ka Shing Knowledge Institute of St. Michael's Hospital (Mamdani, Verma, Al-Omran); Department of Surgery (Hussain, Lindsay, Verma, Al-Omran), University of Toronto; Division of Vascular Surgery (Lindsay), Peter Munk Cardiac Centre, University Health Network; Institute of Health Policy, Management, and Evaluation, and Leslie Dan Faculty of Pharmacy (Mamdani), University of Toronto; Applied Health Research Centre (Mamdani), Toronto, Ont.; King Saud University-Li Ka Shing Collaborative Research Program and Department of Surgery (Mamdani, Verma, Al-Omran), King Saud University, Riyadh, Kingdom of Saudi Arabia; Institute for Clinical Evaluative Sciences (Mamdani, Wang), Toronto, Ont.

Contributors: Mohamad Hussain, Thomas Lindsay, Muhammad Mamdani, Subodh Verma and Mohammed Al-Omran conceived and designed the study. Xuesong Wang acquired the data, and Mohamad Hussain, Thomas Lindsay, Muhammad Mamdani, Xuesong Wang and Mohammed Al-Omran analyzed and interpreted the data. Mohamad Hussain drafted the manuscript. Mohamad Hussain, Thomas Lindsay, Muhammad Mamdani, Subodh Verma and Mohammed Al-Omran critically revised the manuscript for important intellectual content. All of the authors gave final approval of the version to be published and agreed to act as guarantors of the work.

Funding: The study was supported by the divisions of Vascular Surgery, Peter Munk Cardiac Centre, University Health Network, and St. Michael's Hospital, Toronto, Ont., and by the Institute for Clinical Evaluative Sciences. Mohamad Hussain is supported in part by a Canadian Institute for Health Research Canada Graduate Scholarship.

Supplemental information: For reviewer comments and the original submission of this manuscript, please see www.cmajopen.ca/content/4/1/ E124/suppl/DC1

Disclaimer: This study was supported by the Institute for Clinical Evaluative Sciences (ICES), which is funded by an annual grant from the Ontario Ministry of Health and Long-Term Care (MOHLTC). The opinions, results and conclusions reported in this article are those of the authors and are independent from the funding sources. No endorsement by ICES or the Ontario MOHLTC is intended or should be inferred. 